Check for updates

Cite this: Chem. Sci., 2019, 10, 1971

๑ All publication charges for this article have been paid for by the Royal Society of Chemistry

Received 1st November 2018

Accepted 3rd December 2018

DOI: $10.1039 / \mathrm{c} 8 \mathrm{sc} 04885 \mathrm{a}$

rsc.li/chemical-science

\section{Total synthesis of micrococcin P1 and thiocillin I enabled by Mo(vi) catalyst $\uparrow$}

\author{
Siddhartha Akasapu, $\$$ Aaron B. Hinds, (ID $\$$ Wyatt C. Powell (D) \\ and Maciej A. Walczak (D)*
}

Thiopeptides are a class of potent antibiotics with promising therapeutic potential. We developed a novel Mo(vi)-oxide/picolinic acid catalyst for the cyclodehydration of cysteine peptides to form thiazoline heterocycles. With this powerful tool in hand, we completed the total syntheses of two representative thiopeptide antibiotics: micrococcin P1 and thiocillin I. These two concise syntheses (15 steps, longest linear sequence) feature a $\mathrm{C}-\mathrm{H}$ activation strategy to install the trisubstituted pyridine core and thiazole groups. The synthetic material displays promising antimicrobial properties measured against a series of Gram-positive bacteria.
The surge in drug-resistant strains of bacteria poses a major global health threat and the need for expedient discovery of new therapeutics characterized by novel modes of action represents a high priority. ${ }^{1}$ The thiopeptide family of antibiotics contains $\sim 150$ members of post-translationally modified peptides of ribosomal origin that display antibacterial activities against drug-resistant pathogens, including methicillin-resistant Staphylococcus aureus (MRSA). ${ }^{2}$ All thiopeptide antibiotics share a common molecular scaffold involving a nitrogencontaining heterocyclic core decorated with varying numbers of thiazol(in)e rings, assembled into macrocycles or acyclic chains of varying sizes and lengths. ${ }^{2 c}$ The macrocycle, whose size is correlated with molecular targets, is responsible for distinct modes of action, allowing thiopeptides to inhibit bacterial cell growth by means of blocking ribosomal protein synthesis. ${ }^{2 d}$ Because of their unique biological activities and intriguing structure, thiopeptides have received considerable attention from the synthetic community. ${ }^{3}$ However, the lack of concise, scalable, and practical syntheses amenable for rapid molecular modifications limits access to these valuable natural products. In this paper, we report a general approach to the synthesis of thiopeptide antibiotics featuring a novel $\mathrm{Mo}(\mathrm{vI})$ oxide catalyst to promote the cyclodehydration of cysteine residues under mild and neutral conditions and is demonstrated by the preparation of $\mathrm{D}$ series thiopeptides micrococcin P1 (1) $)^{3 u, 3 w, 4}$ and thiocillin I (2), ${ }^{3 x, 5}$ This practical and scalable route is suitable for analogue preparation and site-selective modifications. ${ }^{6}$

Department of Chemistry, University of Colorado, Boulder, CO 80309, USA. E-mail: maciej.walczak@colorado.edu

$\dagger$ Electronic supplementary information (ESI) available. See DOI: 10.1039/c8sc04885a

\$ These authors contributed equally.
Our retrosynthetic analysis of the synthetic targets led to the dissection of the macrocycle into two "top" and "bottom" fragments, which could be united through a peptide coupling and then macrocyclised at the thiazole carboxylic acid adjacent to valine to furnish the final product(s) (Fig. 1). For construction of the two fragments, we envisioned a convergent approach involving the strategic introduction of selected thiazole rings through a catalytic cysteine cyclodehydration. Catalytic methods for cysteine cyclodehydrations are scarce despite the myriad obstacles encountered when employing common stoichiometric reagents due to their high Lewis acidity, likely incompatibility with acid-sensitive groups, possible epimerization, and generation of undesired by-products. ${ }^{7}$ We hypothesized that a $\mathrm{MoO}_{2}(\mathrm{~L})_{2}$ complex with the appropriate ligands might minimize epimerization of the endo- and exocyclic methylene groups since the cyclization event occurs under neutral conditions. Furthermore, bidentate ligands may extend the lifetime of the catalyst and prevent precipitation of heterogeneous molybdenum particles. ${ }^{8}$

To validate the feasibility of this proposal, we evaluated a series of Mo(vi) oxide complexes (Table 1). Initially, we studied

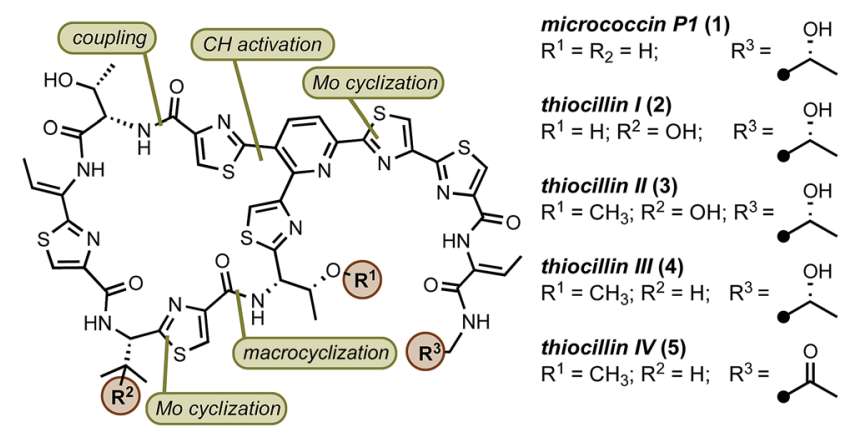

Fig. 1 Selected thiopeptide antibiotics of the D series. 
Table 1 Invention and optimization of $\mathrm{MoO}_{2}(\mathrm{~L})_{2}$-catalyzed cysteine cyclodehydration
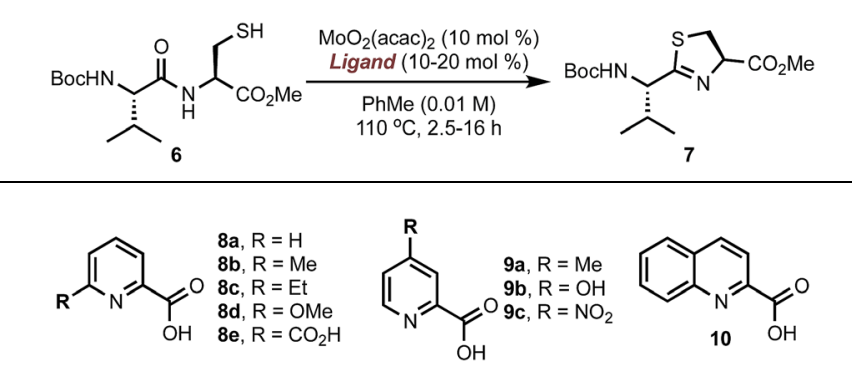

\begin{tabular}{llllllll}
\hline Entry & L & Time & Yield & Entry & L & Time & Yield \\
\hline 1 & None & $16 \mathrm{~h}$ & $18 \%$ & 7 & $\mathbf{8 e}$ & $16 \mathrm{~h}$ & $19 \%$ \\
2 & $\mathbf{8 a}$ & $16 \mathrm{~h}$ & $85 \%$ & 8 & $\mathbf{9 a}$ & $16 \mathrm{~h}$ & $8 \%$ \\
3 & $\mathbf{8 b}$ & $2.5 \mathrm{~h}$ & $87 \%$ & 9 & $\mathbf{9 b}$ & $16 \mathrm{~h}$ & $9 \%$ \\
4 & $\mathbf{8 b}$ & $16 \mathrm{~h}$ & $97 \%$ & 10 & $\mathbf{9 c}$ & $16 \mathrm{~h}$ & $68 \%$ \\
5 & $\mathbf{8 c}$ & $16 \mathrm{~h}$ & $98 \%$ & 11 & $\mathbf{1 0}$ & $16 \mathrm{~h}$ & $62 \%$ \\
6 & $\mathbf{8 d}$ & $16 \mathrm{~h}$ & $26 \%$ & 12 & L-Proline & $16 \mathrm{~h}$ & $<1 \%$
\end{tabular}

the cyclodehydration reaction under conditions using only acac (acetylacetonate) as the ligand (entry 1). We observed that the molybdenum complex precipitated from the solution, forming insoluble particles, resulting in low yields of thiazoline product 7. In order to maximize the conversion of 6 into 7, catalyst loadings of $\mathrm{MoO}_{2}(\mathrm{acac})_{2}$ had to be increased up to $60 \mathrm{~mol} \%$ and the molybdenum complex had to be added portion-wise over a period of $12 \mathrm{~h}$ to ensure reproducible yields. We hypothesized that a bidentate ligand that (a) stabilizes Mo, preventing the formation of heterogeneous particles, and (b) modulates the electrophilic character of Mo presented a viable solution to these problems. To this end, we investigated a series of ligands based on the pyridine 2-carboxylate core (entries 2-11). These additives $(20 \mathrm{~mol} \%)$ were pre-mixed with $\mathrm{MoO}_{2}(\mathrm{acac})_{2}$ $(10 \mathrm{~mol} \%)$ and used directly in the cyclodehydration reactions with 6. Addition of picolinic acid $8 \mathbf{8}$ was sufficient to improve the yield of 7 to $85 \%$ (entry 2) whereas carboxylates with electron-donating groups such as $\mathbf{8 d}, \mathbf{9 a}$, 9b gave 7 in $<30 \%$ yield. Although still suboptimal, electron-poor ligands (entries 10 and 11) improved conversion of 6 into 7 with respect to the original conditions using only the acac ligand. The geometry of the Mo centre is also important as demonstrated by the reaction with bis-acid 8e forming a tridentate complex with Mo (entry 7). We found that a combination of sterics at $\mathrm{C} 6$ and a moderate electron-donating ability of the substituent resulted in excellent yields of 7 with $<1 \%$ epimerization (entries 3-5). Although 6methyl- and 6-ethylpyridine carboxylates gave comparable results (entries 2-5), we elected to use $\mathbf{8 b}$ as the ligand for further studies because of the significant cost difference between these two reagents. For comparison, a ligand with a basic $\mathrm{sp}^{3}$ nitrogen completely suppressed the reaction (entry 12). To exclude the possibility that the cyclodehydration reactions are catalyzed by a Brønsted acid, thiol 6 was exposed to catalytic amounts of pTSA (10 mol\%) or $\mathbf{8 b}(10 \mathrm{~mol} \%)$ under otherwise identical conditions from Table 1 and gave 7 in $<1 \%$ after $16 \mathrm{~h}$ at $110{ }^{\circ} \mathrm{C}$.
We rationalized the reactivity trend from Table 1 by a mechanism depicted in Scheme 1A: complex 11 undergoes a ligand exchange with amide 12, replacing one of the pyridine coordination sites. Picolinic acid-based ligands that contain electron-donating groups (e.g., 8d, 9a, 9b) retard the initial displacement step because the electron-rich heterocycle forms a tighter complex with the electrophilic $\mathrm{Mo}(\mathrm{vI})$, whereas electron-withdrawing groups at $\mathrm{C} 4$ and $\mathrm{C} 6$ of the pyridine ring (e.g., 9c) facilitate the displacement. Once the amide is bound to Mo (13), a proton transfer occurs from the amide $\mathrm{NH}$ to one of the oxo ligands. This step is likely promoted by a neighbouring nitrogen atom on the pyridine ring and may proceed intramolecularly. Ring closure from 14 followed by elimination of $\mathrm{H}_{2} \mathrm{O}$ and azoline product 16 regenerates catalyst 11 . The highest rate of cyclodehydration of $\mathbf{6}$ with $\mathbf{8 b}$ can be rationalized by its electron-donating ability combined with steric hindrance of the methyl group that likely distorts the geometry of the $\operatorname{MoO}_{2}\left(\mathrm{~L}_{2}\right)$ complex, thus accelerating access of the amide substrate. This mechanistic proposal is consistent with DFT calculations (Scheme 1B). The most stable configuration of the $\mathrm{MoO}_{2}(\mathrm{pic})_{2}$ complex is the one with pyridine nitrogen atoms in a cis configuration (e.g., 11). The Mo-N bond in the unsubstituted picolinic acid complex is $2.38 \AA$. This linkage is elongated in complexes substituted at $\mathrm{C} 4$ with an electron-withdrawing group (9c) and in sterically-congested complexes with the 6-Me group making the initial ligand exchange more facile. On the contrary, attachment of an electron-donating group at the para position increases the bond strength between Mo and N, demonstrated by a shortened Mo-N distance in a complex with 9 a.

Having established a robust method for the catalytic installation of select thiazole groups, we proceeded towards the preparation of bottom fragments 25 (Scheme 2). The optimized

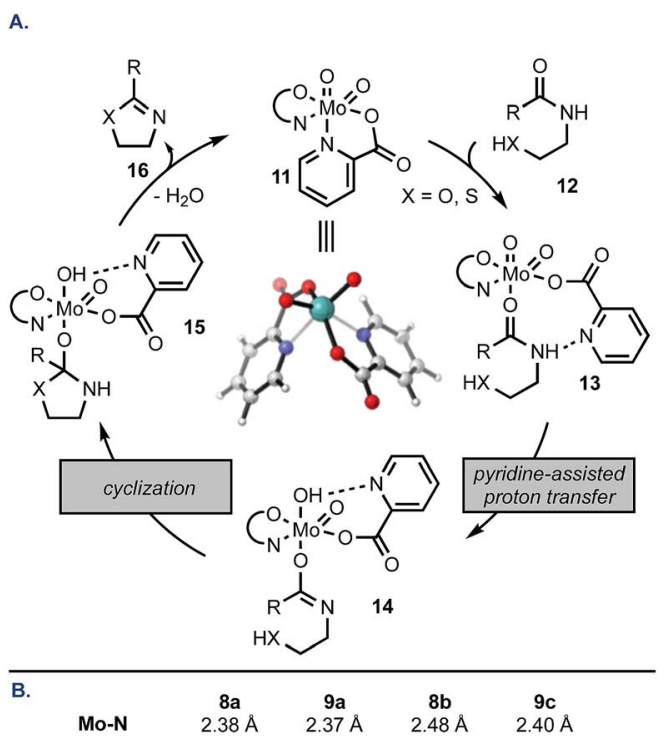

Scheme 1 (A) Proposed mechanism of Mo-catalysed cyclodehydration (second carboxylate ligand abbreviated for clarity). (B) Selected geometrical parameters of $\mathrm{MoO}_{2}(\mathrm{X})_{2}$ complexes optimized at B3LYP/6-31G(d)/LANL2DZ level of theory. The optimized structure of the thermodynamic complex of $\mathrm{MoO}_{2}(\text { pic })_{2}$, pic $=2$-picolinate is presented in the middle of the catalytic cycle. 
cyclodehydration conditions were applied to two dipeptides $\mathbf{1 7}$ followed by oxidation to thiazoles 18 in excellent yields for both substrates. The remaining portion of the bottom fragment was prepared via a modified Hantzsch method using thioamide 19 and bromopyruvate 20 in $94 \%$ yield. Coupling of 21 with serine 22 followed by a stereoselective $(\mathrm{dr}>99: 1)$ installation of the trisubstituted olefin with $\mathrm{MsCl}$ and a base (DABCO, $\mathrm{Et}_{2} \mathrm{NH}$ ) resulted in thiazole 24 . With this key precursor in hand, the amine and carboxylate groups in $\mathbf{1 8}$ and $\mathbf{2 4}$ were liberated and the subsequent amide couplings resulted in gram-scale syntheses of bottom fragments 25 in seven steps for both micrococcin P1 and thiocillin I in 47\% and 51\% overall yield, respectively.

The synthesis of top fragment 37, common to D series thiopeptides, started from a Pd-catalyzed $\mathrm{C}-\mathrm{H}$ activation of thiazole 26 (Scheme 3). We found that the yield of this reaction was critically dependent on the size of the ester group and the methyl group was incompatible with the cross-coupling conditions. The reaction of ethyl thiazole ester $\mathbf{2 6 \mathbf { b }}$ with $\mathrm{Pd}(\mathrm{OAc})_{2}$ (5 mol\%) and CyJohnPhos (15 mol\%) gave, after conversion

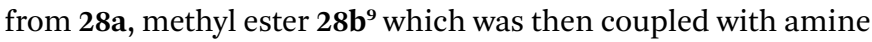
30 following the two-step, selective chlorination of the pyridine core $(97 \%)$. At this stage, the sulfur protective group was removed, and $\mathrm{MoO}_{2}(\mathrm{acac})_{2}$-catalyzed cyclodehydration and oxidation afforded 32 in $86 \%$ yield. We found that the pyridine
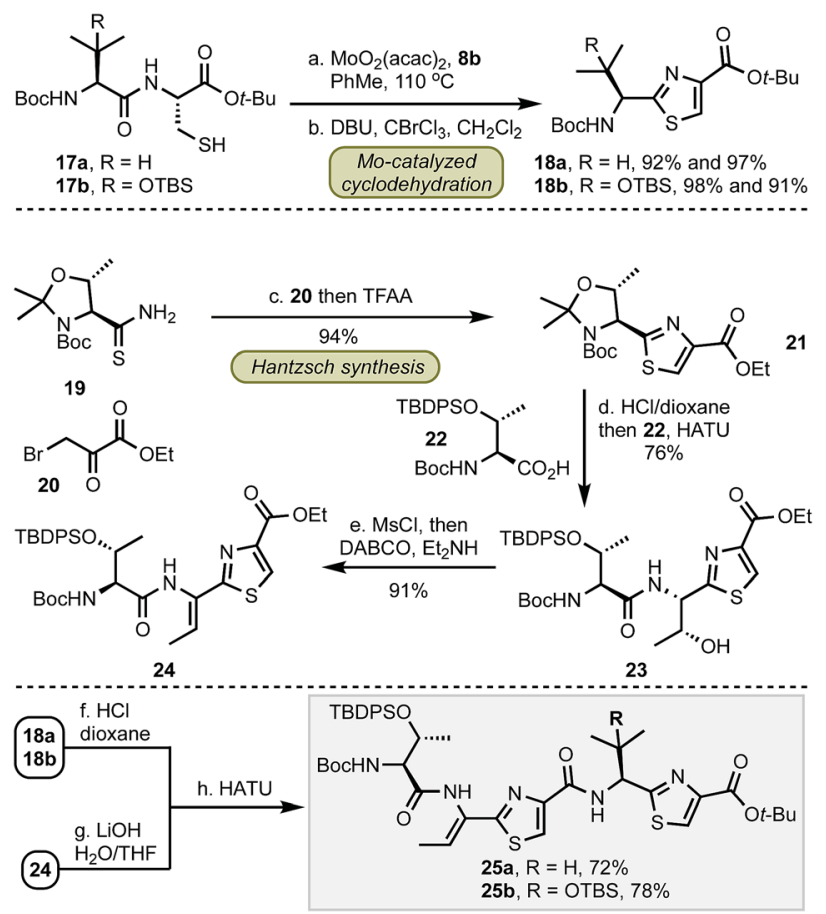

Scheme 2 Synthesis of bottom fragments 25 . (a) $\mathrm{MoO}_{2}(\mathrm{acac})_{2}$ (10 mol\%), 8b (20 mol\%), PhMe, $110{ }^{\circ} \mathrm{C}, 2.5 \mathrm{~h}: 18 \mathrm{a}-92 \%, 18 \mathrm{~b}-98 \%$; (b) $\mathrm{DBU}, \mathrm{CBrCl}_{3}, \mathrm{CH}_{2} \mathrm{Cl}_{2}, 0^{\circ} \mathrm{C}, 1 \mathrm{~h}: 18 \mathrm{a}-97 \%, 18 \mathrm{~b}-91 \%$; (c) $20, \mathrm{NaHCO}_{3}$, THF, $0{ }^{\circ} \mathrm{C}$ to $\mathrm{rt}, 16 \mathrm{~h}$ then pyridine, TFAA, $0{ }^{\circ} \mathrm{C}, 20 \mathrm{~min}, 94 \%$; (d) $\mathrm{HCl}$, 1,4-dioxane, $\mathrm{rt}, 7 \mathrm{~h}$ then $22, \mathrm{HATU}, \mathrm{DIPEA}, \mathrm{DMF}, 0{ }^{\circ} \mathrm{C}$ to $\mathrm{rt}, 1 \mathrm{~h}, 76 \%$; (e) $\mathrm{MsCl}, \mathrm{Et}_{3} \mathrm{~N}, \mathrm{CH}_{2} \mathrm{Cl}_{2}, 0{ }^{\circ} \mathrm{C}, 1 \mathrm{~h}$ then DABCO, $\mathrm{Et}_{2} \mathrm{NH}, 0{ }^{\circ} \mathrm{C}$ to $\mathrm{rt}, \mathrm{CH}_{2} \mathrm{Cl}_{2}$, $16 \mathrm{~h}, 91 \%$; (f) $\mathrm{HCl}, 1,4$-dioxane, $0{ }^{\circ} \mathrm{C}$ to rt, $45 \mathrm{~min}$; (g) $\mathrm{Bu}_{2} \mathrm{SnO}, \mathrm{MeOH}$, $80{ }^{\circ} \mathrm{C}, 4 \mathrm{~h}$ then $\mathrm{LiOH}, \mathrm{H}_{2} \mathrm{O} / \mathrm{THF}, 90 \%$ (over two steps); (h) HATU, DIPEA, DMF, $0{ }^{\circ} \mathrm{C}$ to rt, $2 \mathrm{~h}: 25 \mathrm{a}-72 \%, 25 \mathrm{~b}-78 \%$. scaffold in $\mathbf{3 1}$ was sufficient to stabilize the $\mathrm{Mo}(\mathrm{vI})$ catalyst and prevented decomposition of the Mo complex in the cyclodehydration reaction thus alleviating the need of further stabilization by additional ligands. Next, the Stille coupling with ethyl vinyl ether 33 followed by bromination with NBS afforded bromoketone 34. Inspired by the prior work of Williams, ${ }^{\mathbf{1 0}}$ we converted 34 into thiazole 36 in $86 \%$. Because the exocyclic methylene group in the Hantzsch intermediate can undergo epimerization, we optimized the cyclization step by buffering the conditions with a bulky base (2,6-lutidine) whereas larger bases (e.g., 2,6-di-t-butyl-pyridine) were ineffective in promoting this transformation. To confirm the optical purity of the newly formed thiazole $\mathbf{3 6}$, the carbamate was removed, and the resultant amine was converted into a Mosher amide giving a 95 : $5 \mathrm{dr}$ (determined by ${ }^{19} \mathrm{~F}$ NMR). Finally, site-selective hydrolysis of the methyl ester in 36 proceeded without concomitant removal of the i-Pr group to yield top fragment 37 in $73 \% .^{3 l}$

In preparation for the union of the two fragments, the Boc protective group was removed from bottom segments 25 to yield free amines 38 which were then coupled with top unit 37 to afford oligopeptides 39. Next, the i-Pr ester in 39 was removed under more forcing conditions $\left(\mathrm{NaOH} / \mathrm{H}_{2} \mathrm{O}\right)$, and the resultant acid was merged with dipeptide 43 . The installation of the olefin was accomplished by elimination of the hydroxyl group in threonine with $\mathrm{MsCl}$ in exclusive $Z$ selectivity. The final steps of the synthesis involved global deprotection with $\mathrm{HCl}$ to cleave all alcohol, amine, and carboxylic acid protective groups in one step, followed by macrocyclization of the resulting amino acid intermediate with PyAOP furnished micrococcin P1 1 in 22\% yield. The similarity of micrococcin P1 and thiocillin I, which differ only by a mutation of L-valine into 3-hydroxy-L-valine, led us to adopt identical conditions for both syntheses, with the exception of the deprotection for thiocillin I. We found that acidic conditions alone were insufficient and resulted in only partial cleavage of the silicon group at the hydroxyvaline position (ca. 30\%); thus, following the final macrocyclization, the resultant precursor was subjected to TBAF to reveal thiocillin I (2) in 15\%. Micrococcin P1 was completed in 14 steps and thiocillin I was completed in 15 steps from known commercial materials (longest linear sequence).

Having access to two representative members of the thiopeptide family, we evaluated the in vitro antimicrobial activity against a panel of recent Gram-positive bacterial strains (Table 2). Micrococcin P1 and thiocillin I exhibited similar potencies, showing 2- to 4 -fold difference in their minimum inhibitory concentration (MIC) values in nearly all of the test bacterial isolates. An exception to this trend was observed for $B$. subtilis ATCC 6633, where micrococcin P1 was inactive at $16 \mu \mathrm{g}$ $\mathrm{mL}^{-1}$ while thiocillin I displayed activity at concentrations as low as $4 \mu \mathrm{g} \mathrm{mL}{ }^{-1}$, a result comparable to a previously published report showing thiocillin $\mathrm{I}$ as active at $1.56 \mu \mathrm{g} \mathrm{mL} \mathrm{m}^{-1}$ against $B$. subtilis PCI 219. ${ }^{5}$ Additionally, micrococcin P1 and thiocillin I were more potent than comparator antibiotics against vancomycin-resistant E. faecalis.

In summary, we described a general synthetic route toward thiopeptide antibiotics belonging to the D series. Given the 
A.<smiles>[R]OC(=O)c1cscn1</smiles>

a. $\mathrm{Pd}(\mathrm{OAc})_{2}, \mathrm{Cy}$-JohnPhos $\mathrm{Cs}_{2} \mathrm{CO}_{3}, \mathrm{DMF}, 110^{\circ} \mathrm{C}$

see table below

CH activation
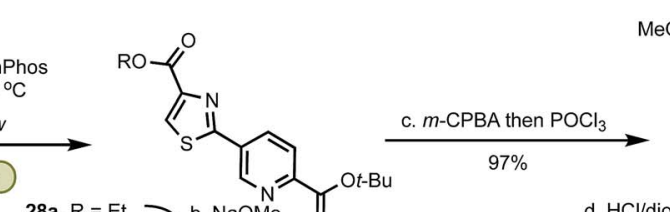

28a, $R=E t$ b. $\mathrm{NaOM}$
$99 \%$

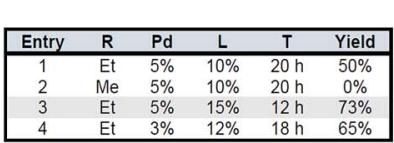
$\mathrm{MeO}-1$

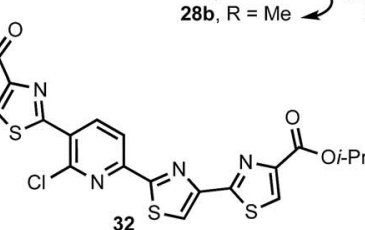

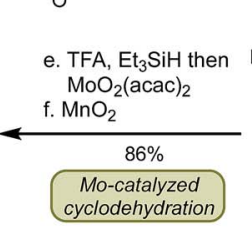

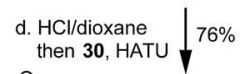<smiles>O=Cc1ccc[nH]1</smiles><smiles>CC(=C(Cl)I)c1nc(C(=O)O)cs1</smiles><smiles></smiles>

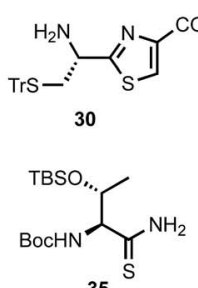

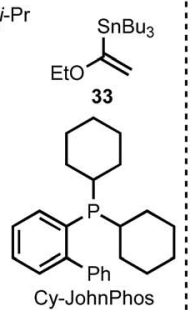<smiles>CCOC(=O)c1csc(-c2ccc(-c3nc(-c4nc(C(=O)OC)cs4)cs3)nc2C(=O)CBr)n1</smiles><smiles>[R]OC(=O)c1csc(-c2ccc(-c3nc(-c4nc(C(=O)OCC)cs4)cs3)nc2-c2csc(C(NC(=O)OCc3ccccc3)C(C)OC(=O)c3ccccc3)n2)n1</smiles>

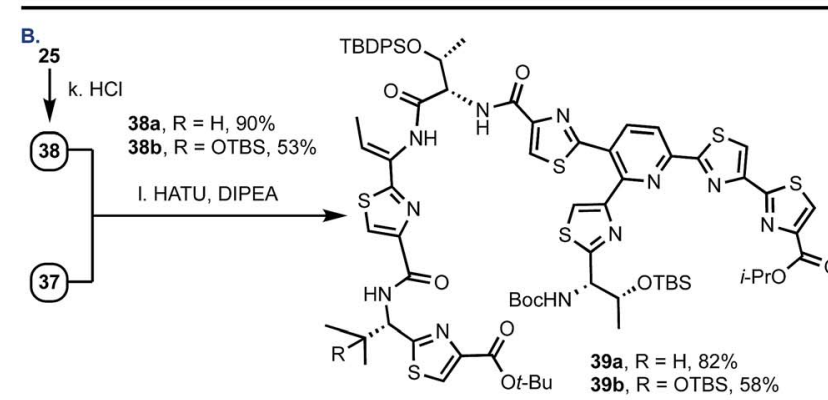
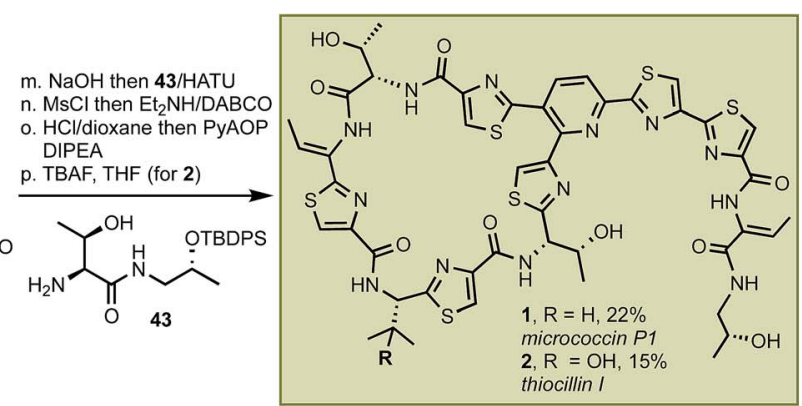

Scheme 3 Preparation of the top fragment and completion of the syntheses. (a) $\mathrm{Pd}(\mathrm{OAc})_{2}(5 \mathrm{~mol} \%), \mathrm{CyJ}_{0} \mathrm{OhnPos}(15 \mathrm{~mol} \%), \mathrm{Cs}_{2} \mathrm{CO} 3, \mathrm{DMF}$, $110{ }^{\circ} \mathrm{C}, 12 \mathrm{~h}, 73 \%$; (b) $\mathrm{NaOMe}, \mathrm{MeOH},-20$ to $0{ }^{\circ} \mathrm{C}, 99 \%$; (c) i - m-CPBA, $\mathrm{CH}_{2} \mathrm{Cl}_{2}$, rt, 2 d; ii $-\mathrm{POCl}_{3}, \mathrm{DMF}, 0{ }^{\circ} \mathrm{C}, \mathrm{CH}_{2} \mathrm{Cl}_{2}, 97 \%$ (over two steps); (d) $\mathrm{HCl}$, 1,4-dioxane, rt, $9 \mathrm{~h}$ then 30, HATU, DIPEA, DMF, $0{ }^{\circ} \mathrm{C}$ to rt, $2 \mathrm{~h}, 72 \%$; (e) i - TFA, $\mathrm{Et}_{3} \mathrm{SiH}, \mathrm{CH}_{2} \mathrm{Cl}_{2}, 0{ }^{\circ} \mathrm{C}, 1 \mathrm{~h}$ then MoO ${ }_{2}(\mathrm{acac}) 2(10 \mathrm{~mol} \%), \mathrm{PhMe}$, $110^{\circ} \mathrm{C}, 13 \mathrm{~h}$; (f) $\mathrm{MnO}_{2}, \mathrm{CH}_{2} \mathrm{Cl}_{2}, \mathrm{rt}, 24 \mathrm{~h}, 86 \%$ (from 31); (g) 33, $\mathrm{PdCl}_{2}\left(\mathrm{PPh}_{3}\right)_{2}\left(10\right.$ mol\%), 1,4-dioxane, $90^{\circ} \mathrm{C}, 18 \mathrm{~h}, 97 \%$; (h) NBS, THF, pH 7 phosphate buffer, rt, $1 \mathrm{~h}, 79 \%$; (i) i $-35, \mathrm{KHCO}_{3}$, dimethoxyethane, $-40{ }^{\circ} \mathrm{C}$ to rt, $24 \mathrm{~h}$ then TFAA, 2,6-lutidine, dimethoxyethane, $-20{ }^{\circ} \mathrm{C}, 20 \mathrm{~h}, 85 \%$; (j) $\mathrm{Me}_{3} \mathrm{SnOH},\left(\mathrm{CH}_{2} \mathrm{Cl}\right)_{2}, 80{ }^{\circ} \mathrm{C}, 20 \mathrm{~h}, 73 \%$; (k) HCl, 1,4-dioxane, $0{ }^{\circ} \mathrm{C}$ to rt, 30-45 min: 38a - 90\%, 38b - 53\%; (l) HATU, DIPEA, DMF, $0{ }^{\circ} \mathrm{C}$ to rt, $2 \mathrm{~h}$ : 39a - 82\%, 39b-53\%; (m) NaOH, MeOH, $0{ }^{\circ} \mathrm{C}$ to rt, $2 \mathrm{~h}$ then 43, HATU, DIPEA, DMF, $0{ }^{\circ} \mathrm{C}$ to rt, $2 \mathrm{~h}$; (n) $\mathrm{MsCl}, \mathrm{Et}_{2} \mathrm{NH}^{\circ} \mathrm{CH}_{2} \mathrm{Cl}_{2} 0{ }^{\circ} \mathrm{C}$ to rt, $15 \mathrm{~min}$ then $\mathrm{DABCO}, \mathrm{Et}_{2} \mathrm{NH}, \mathrm{CH}_{2} \mathrm{Cl}_{2}, \mathrm{O}^{\circ} \mathrm{C}$ to rt, $2.5 \mathrm{~d}$; (o) $\mathrm{HCl}, 1,4$-dioxane, $\mathrm{rt}, 16 \mathrm{~h}$ then PyAOP, DIPEA, DMF, $-20{ }^{\circ} \mathrm{C}, 30 \mathrm{~min}, 22 \%$ (for 1 from $39 \mathrm{a}$ ); (p) TBAF, $\mathrm{THF}, 0{ }^{\circ} \mathrm{C}, 1-2 \mathrm{~h}, 15 \%$ (for 2 from 39b).

Table 2 Minimum inhibitory concentration (MIC) values for micrococcin P1 and thiocillin I

\begin{tabular}{llllll}
\hline & \multicolumn{5}{c}{$\mathrm{MIC}\left(\mu \mathrm{g} \mathrm{\textrm {mL } ^ { - 1 } )}\right.$} \\
\cline { 3 - 6 } Isolate & & 1 & 2 & Vancomycin & Ciprofloxacin \\
\hline S. aureus & ATCC 29213 & 4 & 2 & 1 & 0.5 \\
& 1974149 & 2 & 2 & 0.5 & 0.25 \\
& 1974148 & 8 & 2 & 1 & $>16$ \\
E. faecalis & 1674621 & 1 & 0.5 & 0.5 & 1 \\
& 1674614 & 1 & 0.5 & $>16$ & $>16$ \\
B. subtilis & ATCC 6633 & $>16$ & 4 & 0.25 & 0.06 \\
S. pyogenes & 1744264 & 1 & 0.5 & 0.5 & 0.25 \\
\hline
\end{tabular}

structural commonalities shared by all family members of this class, the presented method is easily adaptable to suit the preparation of thiopeptides belonging to other series as well as derivatives. The novel molybdenum catalyst eliminates the need for stoichiometric reagents and generates water as the only byproduct. Moreover, the modular approach lends itself into future SAR studies to attain compounds with desirable properties for pre-clinical and clinical development.

\section{Conflicts of interest}

There are no conflicts to declare.

\section{Acknowledgements}

This work was supported by the University of Colorado at Boulder and in part by the NSF (CHE-1753225). Mass spectral analyses were recorded by the University of Colorado Boulder Central Analytical Laboratory Mass Spectrometry Core Facility (partially funded by NIH S10 RR026641). Dr Bimala Lama is acknowledged for the assistance with NMR experiments. 


\section{References}

1 (a) M. A. Fischbach and C. T. Walsh, Science, 2009, 325, 1089; (b) C. f. D. C. a. Prevention, Antibiotic Resistance Threats in the United States, 2013; (c) I. B. Seiple, Z. Zhang, P. Jakubec, A. Langlois-Mercier, P. M. Wright, D. T. Hog, K. Yabu, S. R. Allu, T. Fukuzaki, P. N. Carlsen, Y. Kitamura, X. Zhou, M. L. Condakes, F. T. Szczypiński, W. D. Green and A. G. Myers, Nature, 2016, 533, 338; (d) M. F. Chellat, L. Raguž and R. Riedl, Angew. Chem., Int. Ed., 2016, 55, 6600; (e) M. F. Richter, B. S. Drown, A. P. Riley, A. Garcia, T. Shirai, R. L. Svec and P. J. Hergenrother, Nature, 2017, 545, 299; $(f)$ S. E. Rossiter, M. H. Fletcher and W. M. Wuest, Chem. Rev., 2017, 117, 12415.

2 (a) M. C. Bagley, J. W. Dale, E. A. Merritt and X. Xiong, Chem. Rev., 2005, 105, 685; (b) C. Li and W. L. Kelly, Nat. Prod. Rep., 2010, 27, 153; (c) X. Just-Baringo, F. Albericio and M. Álvarez, Angew. Chem., Int. Ed., 2014, 53, 6602; (d) X. Just-Baringo, F. Albericio and M. Álvarez, Mar. Drugs, 2014, 12, 317.

3 (a) C. J. Moody and M. C. Bagley, Chem. Commun., 1998, 2049; (b) C. J. Moody and M. C. Bagley, Synlett, 1998, 361; (c) K. C. Nicolaou, C. N. C. Boddy, S. Bräse and N. Winssinger, Angew. Chem., Int. Ed., 1999, 38, 2096; (d) M. C. Bagley, K. E. Bashford, C. L. Hesketh and C. J. Moody, J. Am. Chem. Soc., 2000, 122, 3301; (e) K. C. Nicolaou, M. Nevalainen, B. S. Safina, M. Zak and S. Bulat, Angew. Chem., Int. Ed., 2002, 41, 1941; $(f)$ C. J. Moody, R. A. Hughes, S. P. Thompson and L. Alcaraz, Chem. Commun., 2002, 1760; $(g)$ K. C. Nicolaou, B. S. Safina, C. Funke, M. Zak and F. J. Zécri, Angew. Chem., Int. Ed., 2002, 41, 1937; (h) K. C. Nicolaou, M. Nevalainen, M. Zak, S. Bulat, M. Bella and B. S. Safina, Angew. Chem., 2003, 115, 3540; (i) R. A. Hughes, S. P. Thompson, L. Alcaraz and C. J. Moody, Chem. Commun., 2004, 946; (j) K. C. Nicolaou, M. Zak, B. S. Safina, S. H. Lee and A. A. Estrada, Angew. Chem., Int. Ed., 2004, 43, 5092; (k) K. C. Nicolaou, M. Zak, B. S. Safina, A. A. Estrada, S. H. Lee and M. Nevalainen, J. Am. Chem. Soc., 2005, 127, 11176; (l) K. C. Nicolaou, A. A. Estrada, M. Zak, S. H. Lee and B. S. Safina, Angew. Chem., Int. Ed., 2005, 44, 1378; $(\mathrm{m})$ K. C. Nicolaou, B. S. Safina, M. Zak, S. H. Lee, M. Nevalainen, M. Bella, A. A. Estrada, C. Funke, F. J. Zécri and S. Bulat, J. Am. Chem. Soc., 2005, 127, 11159; (n) K. C. Nicolaou, B. Zou, D. H. Dethe, D. B. Li and D. Y. K. Chen, Angew. Chem., Int. Ed., 2006, 45, 7786; (o)
H. M. Müller, O. Delgado and T. Bach, Angew. Chem., Int. Ed., 2007, 46, 4771; (p) R. A. Hughes and C. J. Moody, Angew. Chem., Int. Ed., 2007, 46, 7930; (q) T. Mori, S. Higashibayashi, T. Goto, M. Kohno, Y. Satouchi, K. Shinko, K. Suzuki, S. Suzuki, H. Tohmiya, K. Hashimoto and M. Nakata, Chem.-Asian J., 2008, 3, 984; (r) O. Delgado, H. M. Mueller and T. Bach, Chem.-Eur. J., 2008, 14, 2322; (s) T. Mori, S. Higashibayashi, T. Goto, M. Kohno, Y. Satouchi, K. Shinko, K. Suzuki, S. Suzuki, H. Tohmiya, K. Hashimoto and M. Nakata, Chem.-Asian J., 2008, 3, 1013; $(t)$ K. C. Nicolaou, D. H. Dethe, G. Y. C. Leung, B. Zou and D. Y. K. Chen, Chem.-Asian J., 2008, 3, 413; (u) D. Lefranc and M. A. Ciufolini, Angew. Chem., Int. Ed., 2009, 48, 4198; (v) C. Ammer and T. Bach, Chem.-Eur. J., 2010, 16, 14083; (w) M. A. Ciufolini and D. Lefranc, Nat. Prod. Rep., 2010, 27, 330; (x) V. S. Aulakh and M. A. Ciufolini, J. Am. Chem. Soc., 2011, 133, 5900; (y) K. C. Nicolaou, Angew. Chem., Int. Ed., 2012, 51, 12414; (z) X. Just-Baringo, P. Bruno, L. K. Ottesen, L. M. Cañedo, F. Albericio and M. Álvarez, Angew. Chem., Int. Ed., 2013, 52, 7818; (aa) K. P. Wojtas, M. Riedrich, J.-Y. Lu, P. Winter, T. Winkler, S. Walter and H.-D. Arndt, Angew. Chem., Int. Ed., 2016, 55, 9772.

4 T. L. Su, Br. J. Exp. Pathol., 1948, 29, 473.

5 J. Shoji, H. Hinoo, Y. Wakisaka, K. Koizumi and M. Mayama, J. Antibiot., 1976, 29, 366.

6 (a) W. J. Wever, J. W. Bogart and A. A. Bowers, J. Am. Chem. Soc., 2016, 138, 13461; (b) X. Luo, C. Zambaldo, T. Liu, Y. Zhang, W. Xuan, C. Wang, S. A. Reed, P.-Y. Yang, R. E. Wang, T. Javahishvili, P. G. Schultz and T. S. Young, Proc. Natl. Acad. Sci. U. S. A., 2016, 113, 3615.

7 K. C. Majumdar and S. K. Chattopadhyay, Heterocycles in Natural Product Synthesis, Wiley-VCH Verlag \& Co. KGaA, Weinheim, Germany, 2011.

8 (a) A. Sakakura, R. Kondo and K. Ishihara, Org. Lett., 2005, 7, 1971; (b) A. Sakakura, R. Kondo, S. Umemura and K. Ishihara, Adv. Synth. Catal., 2007, 349, 1641; (c) A. Sakakura, S. Umemura, R. Kondo and K. Ishihara, Adv. Synth. Catal., 2007, 349, 551; (d) A. Sakakura, S. Umemura and K. Ishihara, Chem. Commun., 2008, 3561; (e) A. Sakakura, R. Kondo, S. Umemura and K. Ishihara, Tetrahedron, 2009, 65, 2102.

9 T. Martin, C. Verrier, C. Hoarau and F. Marsais, Org. Lett., 2008, 10, 2909.

10 Q. Qiao, S.-S. So and R. A. Goodnow, Org. Lett., 2001, 3, 3655. 